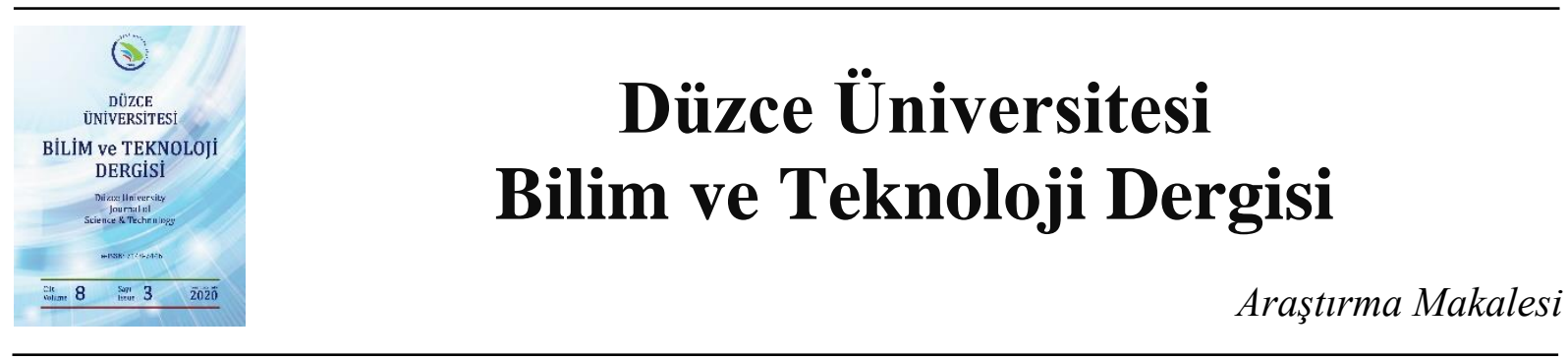

\section{Soğutma Sistemlerindeki Kondenseri Yoğuşma Suyu ile Soğutarak Performansın Arttırılması: Adıyaman İli Örneği}

\author{
D Halil İbrahim VARİYENLİ ${ }^{\text {a }}$ (iD Abdulkadir ŞENER ${ }^{b}$, iD Ataollah KHANLARI ${ }^{c}{ }^{*}$, iD Emine Yağız \\ GÜRBÜZ ${ }^{\text {b,d }}$ \\ ${ }^{a}$ Enerji Sistemleri Mühendisliği Bölümü, Teknoloji Fakültesi, Gazi Üniversitesi, Ankara, TÜRKIYYE \\ ${ }^{b}$ Fen Bilimleri Enstitüsü, Gazi Üniversitesi, Ankara, TÜRKIYYE \\ ${ }^{c}$ Makine Mühendisliği Bölümü, Mühendislik Fakültesi, Türk Hava Kurumu Üniversitesi, Ankara, TÜRKIYE \\ ${ }^{d}$ Enerji Sistemleri Mühendisliği Bölümü, Teknoloji Fakültesi, Muğla Sıtkı Koçman Üniversitesi, Muğla, \\ TÜRKIYYE \\ * Sorumlu yazarin e-posta adresi: ata_khanlari@yahoo.com.tr
} DOI: $10.29130 /$ dubited.723895

\begin{abstract}
ÖZET
Soğutma sistemlerinde ilk yatırım ve işletme maliyetleri ısıtma sistemlerine göre daha yüksektir. Bu nedenle soğutma sistemlerinde yapılacak verimlilik çalışmaları ısıtma sistemlerine göre daha faydalı olacaktır. Kondenser üzerindeki sıcaklığın yüksek olması dış ortam koşullarına bağlı olarak ısısını yeteri kadar atamamasının bir göstergesidir. Isısını istenilen düzeyde atamayan soğutucu akışkan tamamen sıvı hale dönüşmez. Bu da soğutma sisteminin verimini düşürür. Bu çalışmada klima iç ünitesinde oluşan yoğuşma suyunun kondensere aktarılmasının soğutma etkinliği üzerinde olan etkisi deneysel olarak araştırılmıştır. Bu bağlamda, $9000 \mathrm{BTU} / \mathrm{h}$ inverter split klimanın soğutma modunda çalışırken evaporatör üzerinde oluşan yoğuşma suyunun kondensere aktarılması sonucunda enerji tüketimi, ortama üfleme sıcaklığı, evaporatör emme sicaklığı, kondenser üfleme sıcaklığı, kompresör gaz çıkış basıncı, evaporatör gaz giriş ve çıkış basıncı üzerinde etkisi incelenmiştir. Kondenserin üzerine aktarılan yoğuşma suyu soğutucu akışkanın yoğuşmasını kolaylaştırmış, harcanan elektrik sarfiyatında ve evaporatör üfleme sıcaklığında belli bir miktar düşüş sağlamıştır. Evaporatör üfleme sıcaklığının normal sisteme göre \%5-10.8 arasında düştüğü kaydedilmiştir. Üfleme sıcaklığına bağlı olarak soğutulan mahalin sıcaklığında da ortalama \%8 olarak düştüğü görülmüştür. Sonuçlara göre soğutulan mahaldeki sicaklığın azalma oranının dış ortamın nem ve sıcaklığına bağlı olduğu tespit edilmiştir. Ayrıca, kondenser üfleme sıcaklığının maksimum \%6.4 düştüğü tespit edilmiştir.
\end{abstract}

Anahtar Kelimeler: Soğutma sistemi, Kondenser, Yoğuşma suyu, Performans, Enerji tüketimi

\section{Enhancing the Performance of Cooling Systems by Cooling Condenser: Adiyaman Case Study}

\begin{abstract}
Initial investment and operating costs in cooling systems are higher than heating systems. Therefore, efficiency increment in cooling systems will be more useful than heating systems. The high temperature on the condenser is an indicator that it does not adequately release its temperature depending on the external environment conditions. The refrigerant cannot completely liquified when it cannot release its heat in the condenser. This reduces the efficiency of the cooling system. In this study, the effect of transferring condensed water in the inner unit to the
\end{abstract}


condenser on the performance has been investigated experimentally. In this context, air conditioning system (9000 $\mathrm{BTU} / \mathrm{h}$ ) has been selected and condensed water in inner unit of the system has been transferred to the condenser unit. Then the effect of using this modification on energy consumption, average blowing air temperature, suction temperature of evaporator, output pressure of compressor, inlet and outlet pressure of evaporator has been studied. Depending on the blowing temperature, a significant reduction was observed in the temperature of the cooled area. In the modified system, evaporator blowing temperature was decreased between \%5-10.8. According to the results, it was determined that the rate of decrease depends on the humidity and temperature of the external environment. In addition, a maximum reduction of $6.4 \%$ in the condenser blowing temperature was recorded.

Keywords: Cooling system, Condenser, Condensed water, Performance, Energy consumption

\section{GIRIS}

Enerji ihtiyacı her geçen gün ülkeler arasında rekabet oluşturacak bir hızla artmaya devam etmektedir. Binalarda kullandığımız enerjinin büyük bir kısmı 1sıtma veya soğutma amaçlı kullanılmaktadır. Soğutma sistemlerinde ilk yatırım ve işletme maliyetleri 1sıtma sistemlerine göre daha yüksektir. $\mathrm{Bu}$ nedenle soğutma sistemlerinde yapılacak verimlilik çalışmaları 1sıtma sistemlerine göre daha faydalı olacaktır.

Yaygın olarak kullanılan klimaların verimini arttırmak amacıyla farklı yöntemler kullanılmaktadır. Bu yöntemlerden birisi; klima evaporatörü üzerinde oluşan yoğuşma suyunun kondensere aktarılmasıdır. Soğutma sistemleri farklı araştırmacılar tarafından incelenmiştir. Nethaji ve Mohideen (2017) tarafından yapılan çalışmada bir soğutma sisteminin verimini arttırmak için kondenser bölümü şebeke suyu ile soğutulmuştur. Elde edilen sonuçlara göre, \%8-10 arasında enerji tasarrufu sağlanmıştır [1]. Siricharoenpanich vd. (2019) bir klima sistemininin soğutma devresine bir ek 1s1 değiştiricisi yerleştirerek soğutucu akışkanın sıcaklığını düşürerek sistemin performansını arttırmışlardır. Sonuç olarak, sistemin soğutma performans katsayısının \%31 olarak arttığ saptanmıştır [2]. Yang vd. (2020) kuru ve sıcak bir bölgede, bir klima sistemine ek bir sulu soğutucu devre ekleyerek enerji tasarrufuna olan etkisini gözlemlemişlerdir. Yaptıkları değişiklik ile mevcut sistemlere göre \%42.5-64 oranında bir enerji tasarrufu elde etmişlerdir [3]. Harby ve Al-Amri (2019), bir split klima sisteminde havay1 kondensere girmeden önce ön soğutma işlemine tabi tutarak elde edilebilecek enerji tasarrufunu incelemişlerdir. Yapılan çalışmada \%15-22 oranında bir iyileşme görülmüştür [4]. Hajidavalloo (2007), bir soğutma sisteminde verimi arttırmak amaciyla kondenseri soğutarak sistemin toplam verimini arttırmayı hedeflemişlerdir. Yaptıkları modifikasyon ile \%16 enerji tasarrufu sağlamışlardır [5]. Hosoz ve Kilicarslan (2004), hava soğutmalı, su soğutmalı ve evaporatif kondenser olmak üzere üç tip kondenseri farklı soğutma sistemlerinde denemişlerdir. Sonuç olarak, evaporatif kondenserin diğerlerine göre daha iyi olduğu tespit edilmiştir [6]. Heidinger vd. (2018), klimanın kondenserinin soğutulmasının sistem verimi üzerindeki etkilerini deneysel olarak araştırmışlardır. Elde ettikleri sonuçlar bu yöntemin soğutma etkinliği üzerinde olumlu etkisinin olduğunu göstermiştir [7]. Manirathnam vd. (2020) soğutma sisteminin performansını iyileştirmek için soğutucu akışkanının içerisine farklı oranlarda nanoparçacık eklemişlerdir. Soğutucu akışkanının içerisine nanoparçacığın eklenmesi, kondenserde 1sı transferini \%1.77-37.35 oranında arttırmıştır [8]. Raveendran ve Sekhar (2017), ev tipi bir buzdolabının kondenserini şebeke suyu ile soğutarak performansın arttırılmasını hedeflemiştir. Yaptıkları yeni tasarım ile enerji tüketiminde \%21-27 düşüş sağlanmıştır [9]. Erşahin (2017) evaporatör ve kondenser sıcaklıklarının soğutma yüküne bağlı kontrolü ile bir soğutma grubunun veriminin değişimini analiz etmiştir [10]. Akçay (2004) soğutma sisteminde kondenser sicaklığını kontrol edilerek, soğutma sisteminin verimini deneysel olarak incelemiştir. Bu bağlamda soğutma sisteminde, kondenser $5 \mathrm{~g} / \mathrm{s}-50$ g/s debisinde şebeke suyla soğutulmuştur [11]. Başka bir çalışmada Afshari vd. (2020) kompresörün soğutulmasının sistemin toplam performansına etkisini deneysel olarak incelemiştir. Bu kapsamda kompresörün soğutulması için bir fan kullanılmıștır [12]. Afshari vd. (2018) farklı soğutucu akışkanların soğutma ve 1sıtma üzerindeki etkilerini deneysel olarak incelemiştir [13]. Başka bir çalışmada Afshari vd. (2017) soğutucu akışkanların özellikleri ve şarj miktarlarının soğutma sisteminin performansı üzerindeki etkilerini deneysel olarak araştırmıştır [14]. Acül (2008) hava soğutmalı kondenserin enerji verimini arttırmak için boru ağı üzeri su spreyleme yöntemini kullanmıştır [15]. Yıldız (2013) soğutma 
sistemlerinde soğutma kapasitesinin adyabatik nemlendirme yöntemi kullanılarak arttırılabilmesini incelemiştir. Bu çalışmada, nozullu adyabatik nemlendirme sistemi bir soğutma sistemine entegre edilmiş ve gerçek şartlar altında test edilmiştir [16].

Literatürdeki farklı çalışmalar incelendiğinde, soğutma sistemlerinin verimini arttırabilmek için farklı yöntemlerin kullanıldığı görülmüştür. Ortam sıcaklığının yüksek olduğu yerlerde kondenser güneş ışınlarına direkt maruz kalmayacak yerlere konarak verim arttırılmaktadır. Ancak, bunun mümkün olmadığı yerlerde evaporatör üzerinde oluşan yoğuşma suyunun kondenser üzerine aktarılması ile kondenseri soğutarak performansının arttırılması mümkündür. Bu çalışmada ise klima evaporatörü üzerinde oluşan yoğuşma suyunun kondensere aktarılmasının performansa olan etkisi deneysel olarak araştırılmıştır.

\section{MATERYAL VE METOT}

Kondenser üzerindeki sıcaklığın yüksek olması dış ortam koşullarına bağlı olarak 1sısını yeteri kadar atamamasının bir göstergesidir. Isısını istenilen düzeyde atamayan akışkan ise tamamen sıvı hale dönüşmez. $\mathrm{Bu}$ da evaporatörün verimini düşürür. Kondenser çıkış sıcaklığını istenilen düzeyde düşürebilirse evaporatöre giden sıcak gaz önlenmiş olur. Kondenser, 1sısını rahat bir şekilde diş ortama verdiği zaman buhar halindeki soğutucu akışkanın tamamen sıvı hale dönüşmesi kolaylaşır. Soğutma modunda kullanılan klimanın evaporatörüne temas eden hava içerisindeki su buharı yoğunlaşarak su damlacıkları haline gelir. Yoğuşan su cihaz içerisindeki su kabı yolu ile drenaj bağlantısına aktarılarak buradan diş ortama çikartılır. Bu çalışmada klima evaporatöründe oluşan yoğuşma suyunun kondensere aktarılmasının soğutma etkinliği üzerinde olan etkisi deneysel olarak araştırılmıştır. Bu bağlamda, 9000 BTU/h inverter split klimanın soğutma modunda çalışırken evaporatörü üzerinde oluşan yoğuşma suyunun kondensere aktarılması sonucunda enerji tüketimi, ortama üfleme sıcaklığı, iç ünite emme sıcaklığı, kondenser üfleme sıcaklığı, kompresör gaz çıkış basınc1, evaporatör gaz giriş ve çıkış basıncı üzerinde etkisi incelenmiştir. Sistemde kompresör, genleşme valfi, evaporatör ve kondenser gibi ana elemanlar ile elektrik sayacı, sıcaklık sensörleri ve manometreler kullanılmıştır. Soğutma sisteminde soğutucu akışkan olarak R410A gazı kullanılmıştır. Soğutulan mekanın yüksekliği 2,8 m, toplam alanı ise $20 \mathrm{~m}^{2}$ 'dir. Deney setinde kullanılan klimanın bağlantı borularının çapı basma hattı için 1/4" emme hattı için ise 3/8" olarak seçilmiştir. Deneyler esnasında kullanılan soğutma cihazının teknik özellikleri Tablo 1'de verilmiştir.

Tablo 1. 9000 BTU/h inverter split klimanın teknik özellikleri

\begin{tabular}{lcc}
\hline & Teknik Özellikler \\
\hline & İç Ünite & Dış Ünite \\
\hline Güç Kapasite (kW) & 2,6 & 220 \\
Güç Beslemesi (V) & 220 & \\
Güç Sarfiyatı (W) & $100-1240$ & R410A \\
Soğutucu Akışkan & R410A & 55,5 \\
Ses Seviyesi (dBA) & $40 / 34 / 30$ & $770 \times 300 \times 555$ \\
Boyut (mm) & $715 \times 194 \times 285$ & $25,2 / 27,4$ \\
Ăğırık (kg) & $6,8 / 8,9$ & $-15 / 18$ \\
Çalışma Sıcaklığı $\left({ }^{\circ} \mathbf{C}\right)$ & $10-46$ & 0,047 \\
Kondenser Fanı (kW) & & 0,6 \\
Evaporatör Fanı (kW) & 0,022 & \\
Kompresör (kW) & & \\
\hline
\end{tabular}


$9000 \mathrm{BTU} / \mathrm{h}(\sim 2,64 \mathrm{~kW})$ inverter split klima kullanarak bir deney seti hazırlanmıştır. Bu deney seti ile birlikte elektrik sarfiyatı ve evaporatör üfleme sıcaklığı üzerinde oluşacak değişiklik gözlenerek verime olan etkisi deneysel olarak belirlenmiştir. Klima evaporatörü üzerinde oluşan yoğuşma suyunun kondensere aktarılmasının performansa olan etkisinin araştırılması için gerekli ölçümler yapılmıştır. Bunun için ölçü aletleri taşıyıcı sistem üzerinde bir pano oluşturularak yerleştirilmiş, ardından bağlantıları yapılmıştır. İç ve dış ünite bağlantıları yapıldıktan sonra evaporatör üzerinde oluşacak yoğuşma suyunun kondenser üzerine aktarılmasını sağlayacak olan tava yapılarak iskelet kısmına montajı gerçekleştirilmiştir. Şekil 1 ve Şekil 2 hazırlanan deney seti ve deney seti üzerinde yapılan modifikasyonu göstermektedir. Daha sonra deney setinin, deney yapılacak montajı gerçekleştirilerek, performans testleri yapılmıştır.

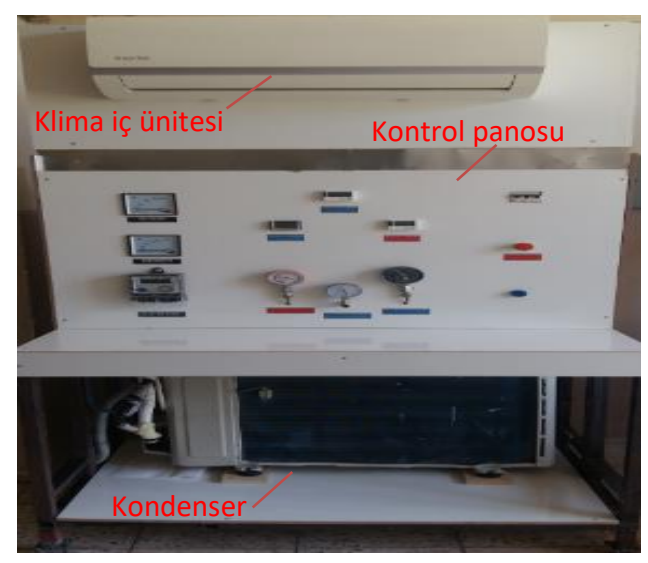

Şekil 1. Inverter split klima deney seti

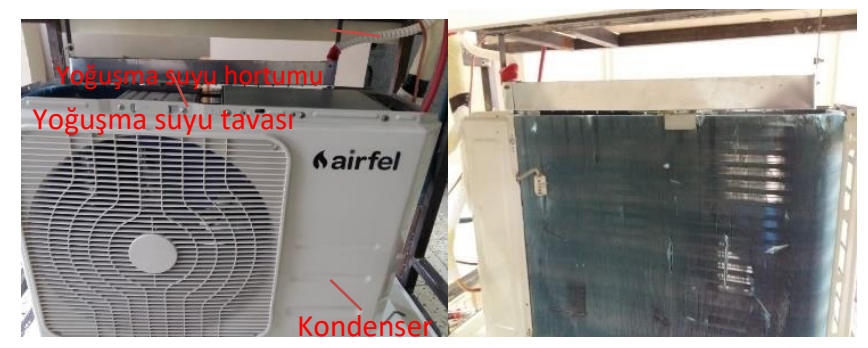

Şekil 2. Yoğuşma suyu tavası ve hortum montajı

\section{SONUCLAR}

Deneyler Adıyaman ilinde 2019 yılı Haziran ayında dış hava sıcaklığının $37{ }^{\circ} \mathrm{C}$ ile $39{ }^{\circ} \mathrm{C}$ olduğu günlerde gerçekleştirilmiştir. Aynı zamanda deneyler sırasında dış havadaki nemin \%16 ile \%20 arasında ve iç havadaki nemin \%21 ile \%27 arasında olduğu ölçülmüştür. Ölçümler klima kararlı hale geldikten sonra yapılmıştır. Klima yaklaşık 60 dakika çalıştırılarak, akım kontrolü, iç-dış ortam sıcaklığı, hava emiş, hava üfleme ve kondenser üfleme sıcaklıkları ölçülmüştür. Kompresör çıkış, evaporatör giriş ve çıkış basınçları ile gaz sıcaklıkları ölçülmüştür. Ölçülen bu değerler kullanılarak yapılan modifikasyonun klimanın verimi üzerindeki etkisi belirlenmiştir.

Tablo 2 ve 3'te klima evaporatörü üzerinde oluşan yoğuşma suyunun kondensere aktarılması ile yapılan deneye sulu sistem, aktarılmadan yapılan deneye ise susuz sistem denilmiştir. Tablo 2'de hava sicaklığının $37^{\circ} \mathrm{C}$ olduğu 25 Haziran 2019 ile 26 Haziran 2019 günlerinde saat 13:30 ile 14:30 arasında gerçekleştirilen çalışmalarda sulu ve susuz sistem olarak yapılan deneylerde ilk veriler, saat 14:30 ile 15:30 arasında yapılan deneylerde ise ikinci veriler elde edilmiştir. 
Tablo 2'deki değerlere baktığımızda sulu sistemde yapılan deneylerin elektrik tüketimi üzerinde az da olsa etkisinin olduğu görülmüştür. Saat 13:30 ile 14:30 arasında yapılan sulu sistem deneyi, susuz sisteme göre $5 \mathrm{~W}$ daha az enerji harcayarak \% 0,51'lik tasarruf sağlamış, deneylere devam edildiğinde ise saat: 14:30 ile 15:30 arasında alınan sonuçlarda 23 W'lık bir fark oluşarak \% 2,23'lük bir tasarruf elde edilmiştir. Tablo 3'te hava sıcaklığının $39{ }^{\circ} \mathrm{C}$ olduğu 27 Haziran 2019 ile 28 Haziran 2019 günlerinde sulu ve susuz sistem olarak saat 13:30 ile 14:30 arasinda yapılan deneylerde ise sulu sistem susuz sisteme göre $9 \mathrm{~W}$ daha az enerji harcayarak \% 0,89'luk tasarruf sağlamış, deneylere devam edildiğinde ise saat 14:30 ile 15:30 arasında alınan sonuçlarda da 52 W'lık bir fark oluşarak \% 4,72'lik bir tasarruf elde edilmiştir. Her iki deneye bakıldığında evaporatör yoğuşma suyunun kondenser üzerindeki etkisi ve buna bağlı olarak da elektrik sarfiyatındaki azalma görülmüştür.

Şekil 3'teki grafiğe baktığımızda deney seti saat 13:30'da hava sıcaklığının en yüksek olduğu zaman diliminde çalıştırılmış, saat $14: 30$ 'da ise elektrik tüketimi bakımından ilk veriler elde edilmiştir. Evaporatör üzerindeki yoğuşma suyu geç oluştuğu için ilk bir saatlik dilimde fazla bir verim elde edilememiştir. Bunun akabinde saat 14:30 ile 15:30 arasında yapılan deneyde yoğuşma suyundaki artıştan dolayı elde edilen verim artmıştır. Şekil 3'teki grafik detaylı bir şekilde incelendiğinde sulu ve susuz sistem olarak yapılan deneylerdeki elektrik tüketimi zamana bağlı olarak değişmektedir. Klima evaporatöründe oluşan yoğuşma suyunun kondensere aktarılması sonucunda elde edilen veriler zamana bağlı olarak değişkenlik gösterdiği için yoğuşma suyu ile elektrik sarfiyatının birbirinden bağımsız olmadığını göstermektedir.

Tablo 2. Sistemin sulu ve susuz olarak çalıştırılması sonucunda harcamış olduğu elektrik sarfiyatı tablosu (dış hava sicakliğ $37^{\circ} \mathrm{C}$ )

\begin{tabular}{|c|c|c|c|c|}
\hline \multirow[b]{3}{*}{ GÜN } & \multicolumn{4}{|c|}{ Hava Sıcaklığı: $37^{\circ} \mathrm{C}$} \\
\hline & \multicolumn{2}{|c|}{ Saat 13:30/14:30 } & \multicolumn{2}{|c|}{ Saat 14:30/15:30 } \\
\hline & $\begin{array}{c}\text { Sulu Sistem } \\
\text { Elektrik Tük. } \\
(W) \\
\end{array}$ & $\begin{array}{c}\text { Susuz Sistem } \\
\text { Elektrik Tük. } \\
(W)\end{array}$ & $\begin{array}{c}\text { Sulu Sistem } \\
\text { Elektrik Tük. } \\
(W)\end{array}$ & $\begin{array}{c}\text { Susuz Sistem } \\
\text { Elektrik Tük. } \\
(W)\end{array}$ \\
\hline 1.Gün & ET: 983 & & ET: 1009 & \\
\hline 2.Gün & & ET: 988 & & ET: 1032 \\
\hline $\begin{array}{c}\text { FARK } \\
\text { (Susuz-Sulu) }\end{array}$ & & & & \\
\hline
\end{tabular}

Tablo 3. Sistemin sulu ve susuz olarak çalıştırılması sonucunda harcamış olduğu elektrik sarfiyatı tablosu (dış hava slcaklĭg $39^{\circ} \mathrm{C}$ )

\begin{tabular}{|c|c|c|c|c|}
\hline \multirow[b]{3}{*}{ GÜN } & \multicolumn{4}{|c|}{ Hava Sicaklığı: $39^{\circ} \mathrm{C}$} \\
\hline & \multicolumn{2}{|c|}{ Saat: 13:30/14:30 } & \multicolumn{2}{|c|}{ Saat: 14:30/15:30 } \\
\hline & $\begin{array}{c}\text { Sulu Sistem } \\
\text { Elektrik Tük. } \\
(W)\end{array}$ & $\begin{array}{c}\text { Susuz Sistem } \\
\text { Elektrik Tük. } \\
(W)\end{array}$ & $\begin{array}{c}\text { Sulu Sistem } \\
\text { Elektrik Tük. } \\
(W)\end{array}$ & $\begin{array}{c}\text { Susuz Sistem } \\
\text { Elektrik Tük. } \\
(W)\end{array}$ \\
\hline 3.Gün & ET: 998 & & ET: 1050 & \\
\hline 4.Gün & & ET: 1007 & & ET: 1102 \\
\hline $\begin{array}{c}\text { FARK } \\
\text { (Susuz-Sulu) }\end{array}$ & \multicolumn{2}{|c|}{ ET: 9} & \multicolumn{2}{|c|}{ ET: 52} \\
\hline
\end{tabular}




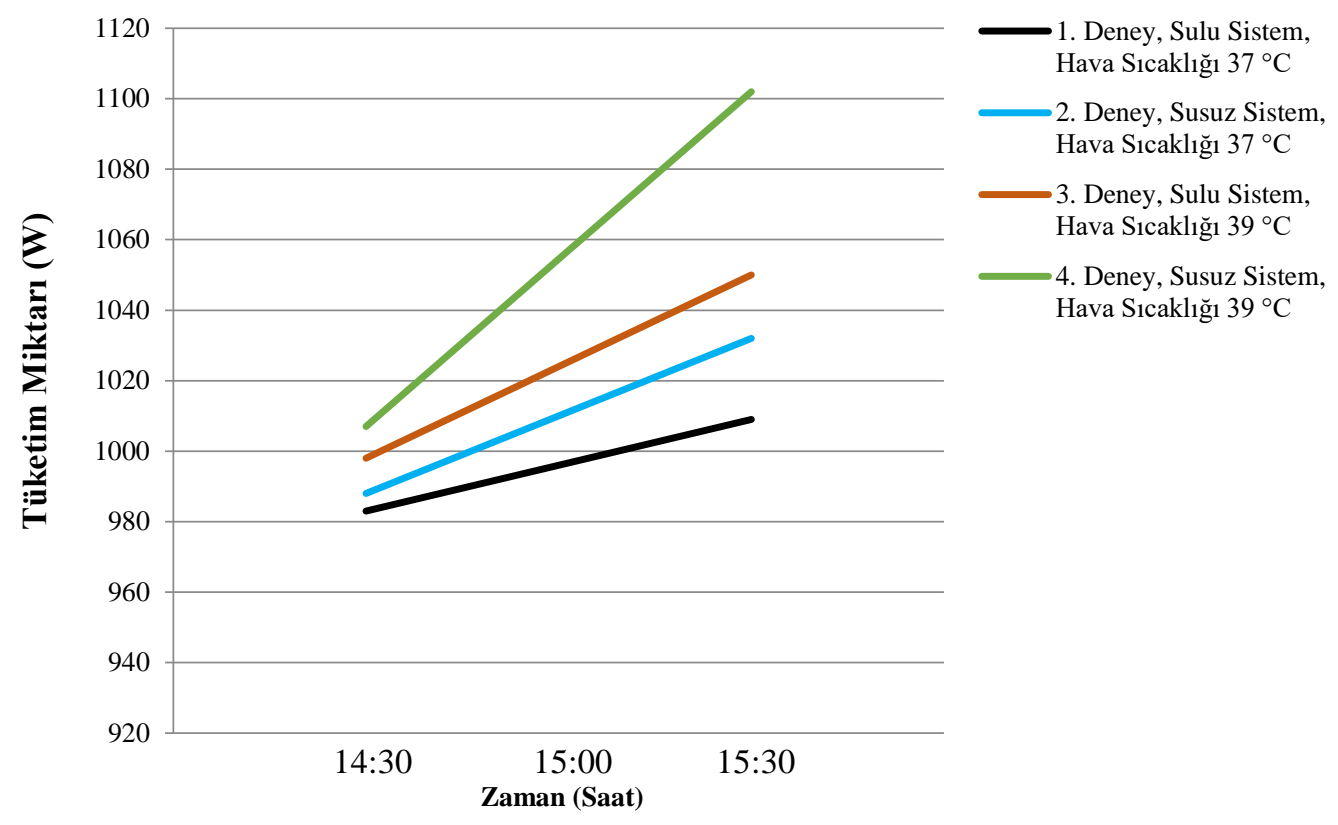

Şekil 3. Elektrik sarfiyatı çizgi grafiği

Şekil 4'te hava sıcaklığının $37^{\circ} \mathrm{C}$, Şekil 5 'te de hava sıcaklığının $39{ }^{\circ} \mathrm{C}$ olduğu günlerde evaporatörde oluşan yoğuşma suyunun kondensere aktarılması ve aktarılmaması sonucunda gerçekleştirilen 1, 2, 3 ve 4 deneylerde en düşük ve en yüksek evaporatör üfleme sıcaklık değerlerinin zamana göre değişimi görülmektedir. Saat 13:30 ile 15:30 arasında gerçekleştirilen deneyler 5'er dakika arayla kaydedilmiştir. Şekil 4 ve Şekil 5'te saat 14:30 ile 15:30 arasında klima evaporatörü üzerindeki yoğuşma suyunun kondensere aktarılması sonucu oluşan üfleme sıcaklık değerlerinin, susuz sisteme göre daha düşük sıcaklıkta seyir ettiği açıkça görülmektedir. Sulu sistemde evaporatör üfleme sıcaklığı, susuz sisteme göre \%5-10,8 arasında düştügü kaydedilmiştir.

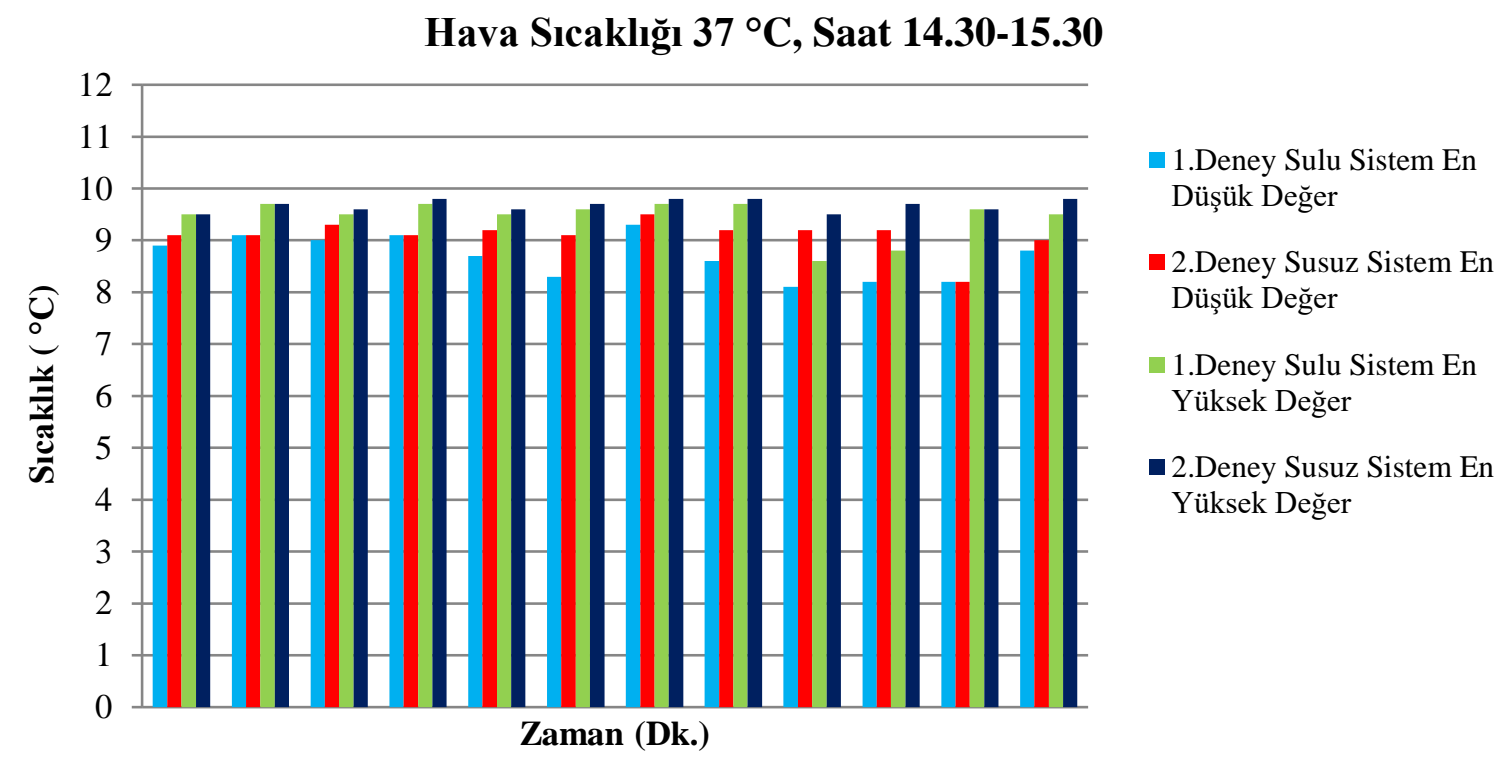

Şekil 4. İç ünite üfleme sıcakllk değerlerinin zamana göre değişimi (dı̧̧ hava sıcaklı̆̆ $37^{\circ} \mathrm{C}$ ) 


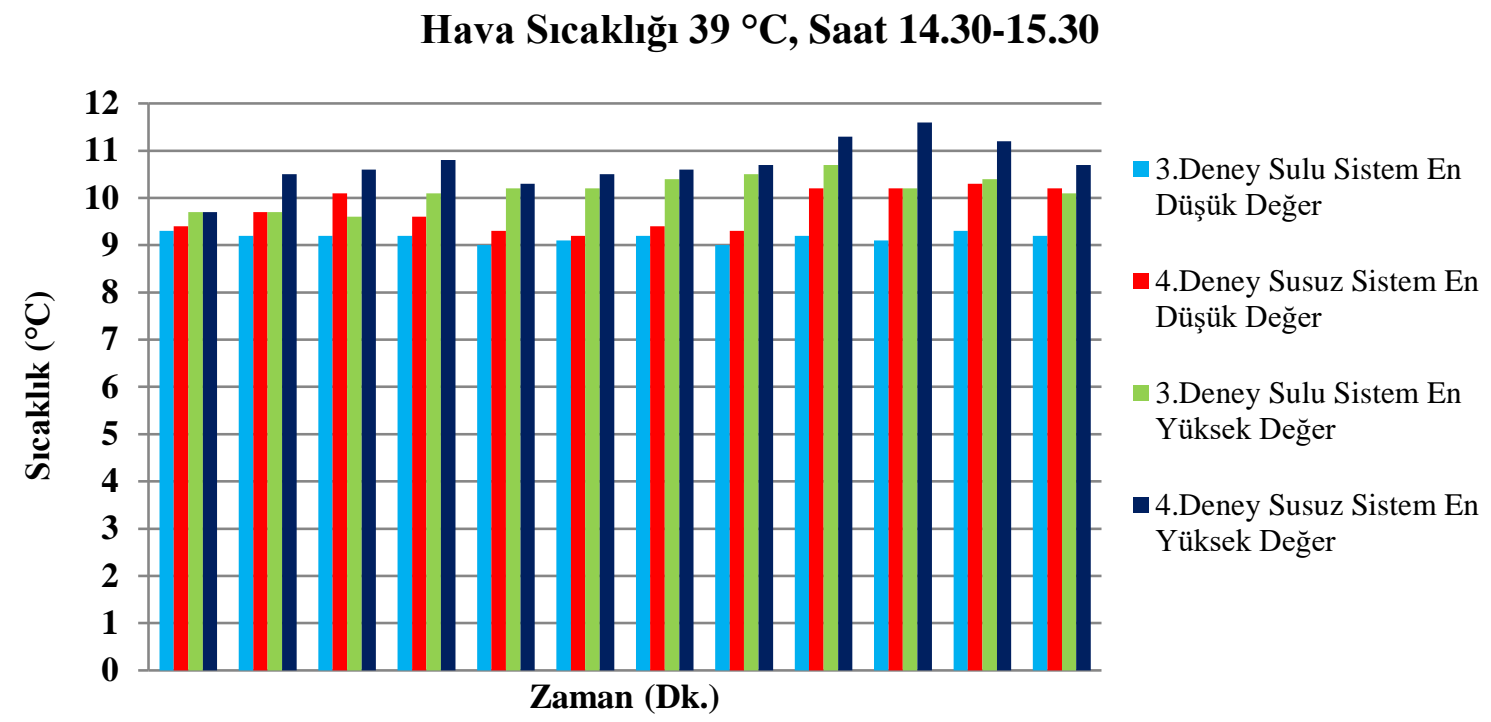

Şekil 5. İç ünite üfleme sıcaklık değerlerinin zamana göre değişimi (dlş hava sıcaklı̆̆l $39^{\circ} \mathrm{C}$ )

Şekil 6'da hava sıcaklığının $37^{\circ} \mathrm{C}$ olduğu günlerde klima evaporatörü üzerindeki yoğuşma suyunun kondensere aktarılması sonucu 1. deney, aktarılmadan ise 2. deney yapılmıştır. Şekil 7'de ise hava sıcaklığının $39^{\circ} \mathrm{C}$ olduğu günlerde klima evaporatörü üzerindeki yoğuşma suyunun kondensere aktarılması sonucu 3. deney, aktarılmadan ise 4. deney yapılmıştır. Yapılan deneyler sonucunda saat 13:30, 14:30 ve 15:30'da yüksek basınç manometresi (kondenser giriş), alçak basınç manometresi (evaporatör giriş) ve alçak basınç manometresinde (evaporatör çıkış) okunan değerler Şekil 6 ile Şekil 7'de verilmiştir. Bu grafiklere baktığımızda sulu ve susuz sistem olarak çalışan deney setinde, manometrelerdeki farkın saat 14:30 ile 15:30'da olduğu görülmektedir. S1caklık ile basınç doğru orantılı olduğundan basınçlardaki değişim üfleme sıcaklıklarındaki değişimi etkilemektedir.

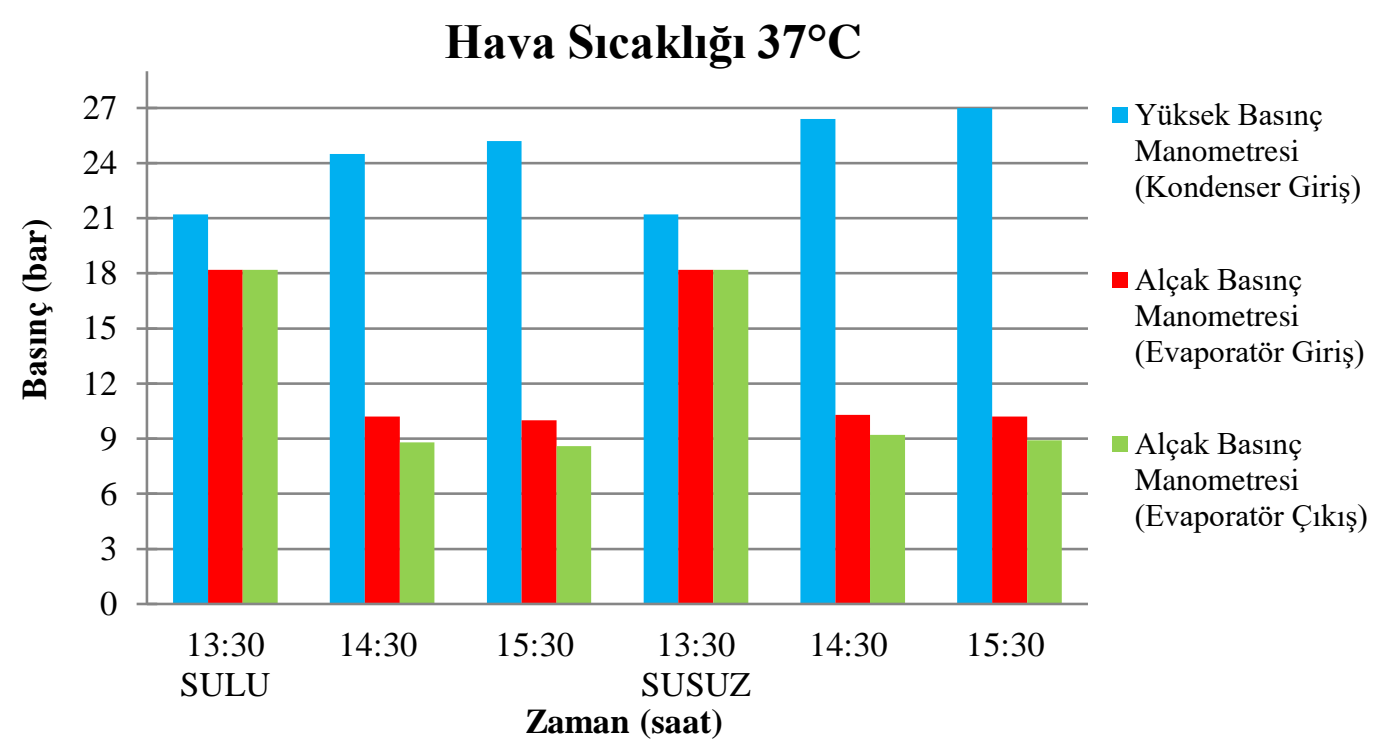

Şekil 6. Yüksek basınç, alçak basınç değerlerinin zamana göre değişimi 


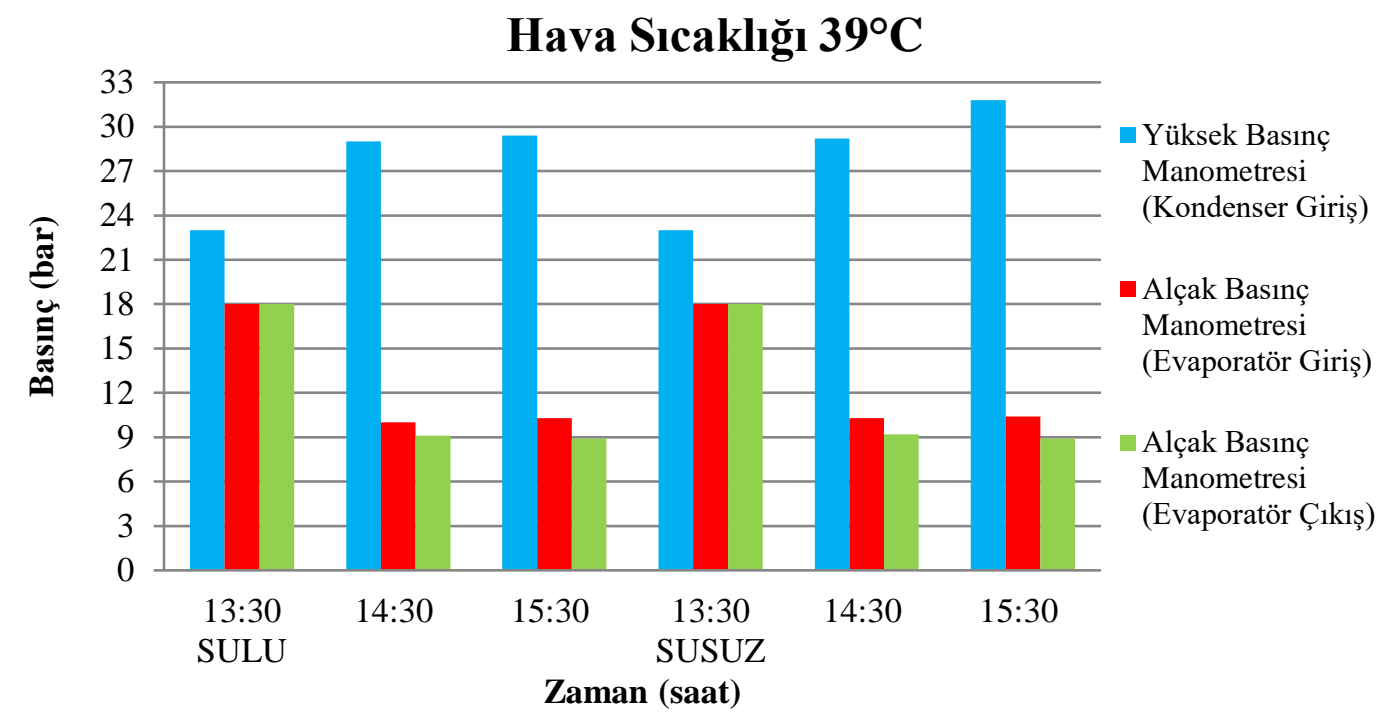

Şekil 7. Yüksek basınç, alçak basınç değerlerinin zamana göre değişimi

Şekil 8'de hava sıcaklığının $37^{\circ} \mathrm{C}$ olduğu, Şekil 9'da ise hava sıcaklığının $39^{\circ} \mathrm{C}$ olduğu günlerde sulu ve susuz sistem olarak yapılan deneylerde kondenser üfleme sıcaklık değerlerinin zamana göre değişimi verilmiştir. Şekil 8'e baktığımızda sulu sistemdeki kondenser üfleme sıcaklık değerleri susuz sisteme göre daha düşük olduğu görülmektedir. Benzer biçimde Şekil 9'da da sulu sistemdeki kondenser üfleme sıcaklık değerleri susuz sisteme göre daha düşük olarak ölçülmüştür. Kondenser üfleme sıcaklğının maksimum \%6,4 düştüğü tespit edilmiştir. Sonuçlarında gösterdiği gibi klima evaporatör üzerinde oluşan yoğuşma suyu kondensere aktarıldığında, kondenserin üfleme sıcaklık değerleri buna bağlı olarak düşmüştür. Böylece, yapmış olduğumuz deney seti ile kondenserin sıcaklığı azalmıştır.

Sıcaklık ölçümlerinde kullanılan termokupl için belirsizlik $\pm 0,58^{\circ} \mathrm{C}$ ve basınç öçümlerinde kullanılan basınç transdüseri için belirsizlik $\pm 1,34$ (\%) olarak elde edilmiştir.

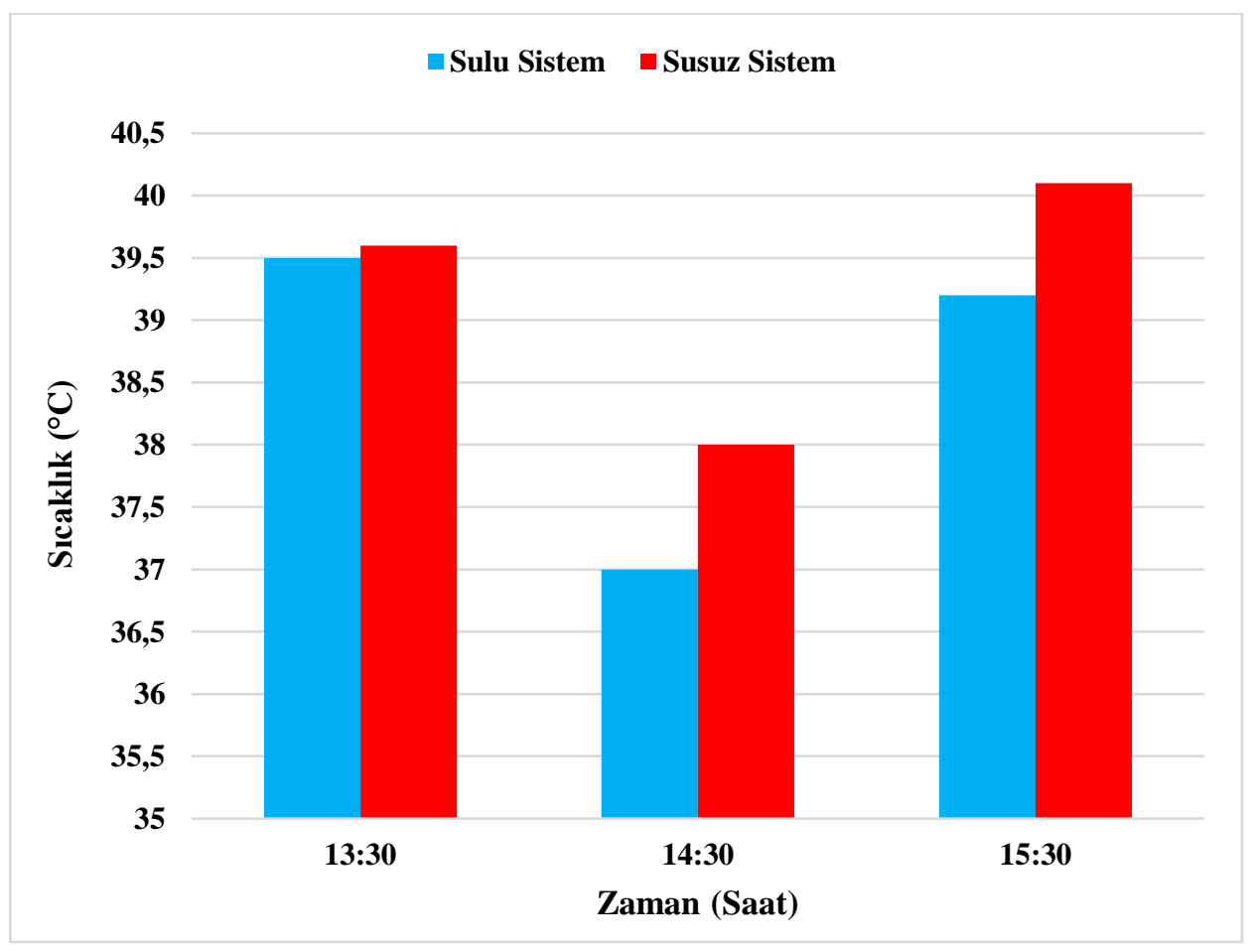

Şekil 8. Dış ünite üfleme sıcaklı̆̆ının zamana göre değişimi 


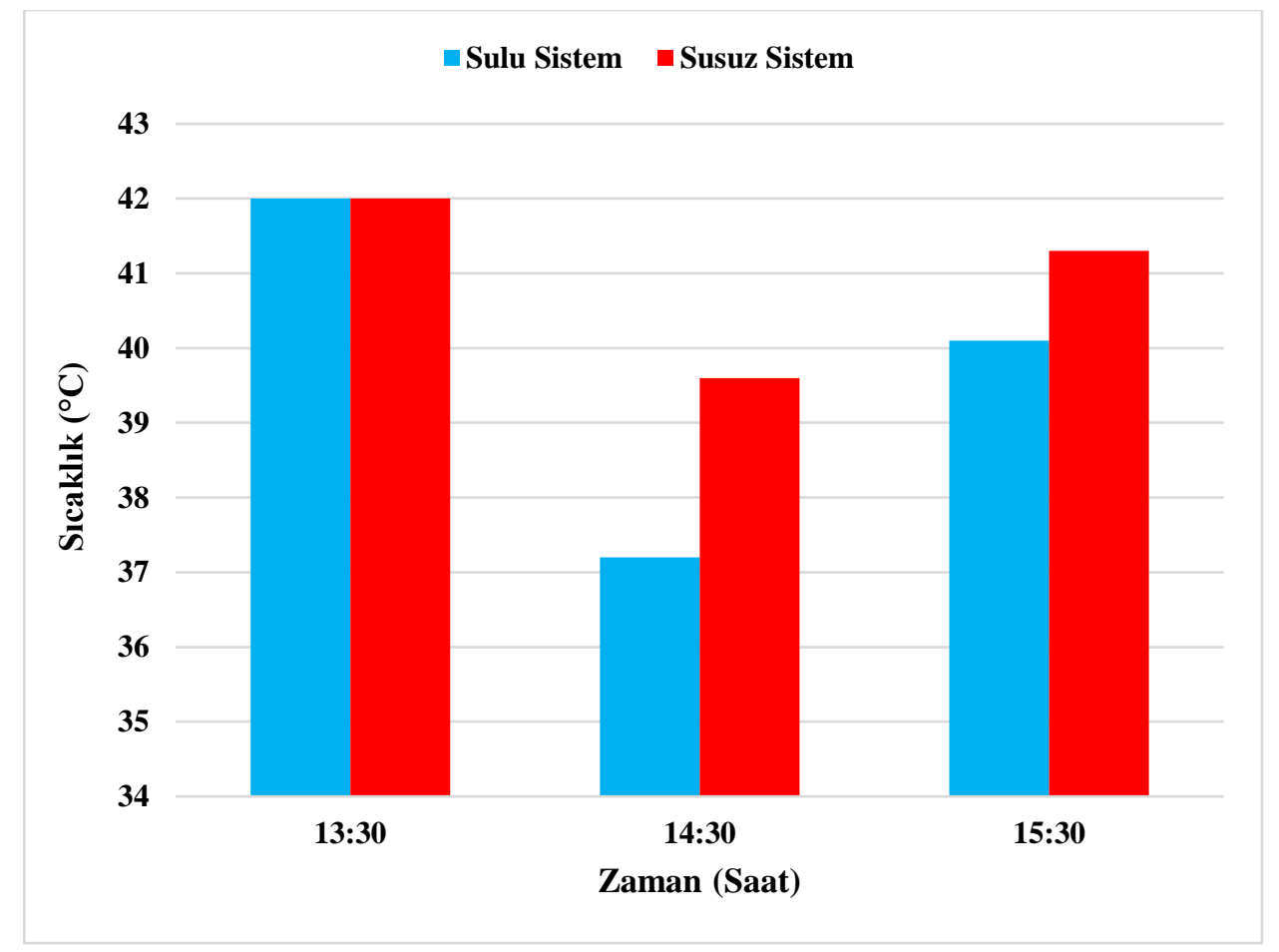

Şekil 9. Dış ünite üfleme sıcaklı̆̆ının zamana göre değişimi

\section{IV.SONUC VE ÖNERILLER}

$\mathrm{Bu}$ çalışma kapsamında evaporatör üzerinde oluşan yoğuşma suyunun kondensere aktarılmasını sağlayan deney seti tasarlanıp imal edilmiştir. Yoğuşma suyunun dış ünite eşanşörüne aktarılmasının amacı, soğutmayı kolaylaştırmak ve enerji tüketimini azaltmaktır. Deneyler Adıyaman ilinde Haziran 2019 ayı içerinde dış hava sıcaklığının $37{ }^{\circ} \mathrm{C}$ ile $39^{\circ} \mathrm{C}$ olduğu günlerde gerçekleştirilmiştir. Enerji tüketimi, ortama üfleme sıcaklığı, dış ünite üfleme sıcaklığı, kompresör gaz çıkış basıncı, evaporatör gaz giriş ve çıkış basıncı gibi veriler toplanarak performans değerlendirmesi yapılmıştır. Evaporatör üfleme sıcaklığının normal sisteme göre \%5-10,8 arasında düştüğü kaydedilmiştir. Ek olarak kondenser üfleme sıcaklığının maksimum \%6,4 düştüğü tespit edilmiştir. Sonuçlara göre, ülkemizde hava sıcaklığının ve nemin yüksek olduğu bölgelerdeki klimaların kondenser sıcaklığını yoğuşma suyu ile düşürerek, elektrik tüketimi ve evaporatör üfleme sicaklığı üzerinde pozitif etki sağlanabileceği deneysel olarak gözlemlenmiştir. Bu yolla fazla bir maliyet harcanmadan, küçük bir değişiklik ile modifiye edilmiş klima sisteminin verimi arttırılmıştır.

Bu çalışma neticesine bağlı olarak daha sonra yapılacak olan çalışmalara aşağıdaki öneriler yapılabilir;

- Yapmış olduğumuz deney nem oranının yüksek olduğu yerlerde yapılırsa verime olan etkisi karşılaştırılabilir.

- Farklı kapasiteli inverter klimalar kullanılarak elektrik tüketimi ve evaporatör üfleme sıcaklığındaki değişiklikler karşılaştırılabilir.

- R410A soğutucu akışkan dışında farklı bir gaz kullanılarak elde edilecek parametreler ile soğutucu akışların mekanik soğutma çevriminde göstermiş olduğu farklılıklar karşılaştırılabilir.

- Fan devri 1. kademe dışında çalıştırılarak elektrik tüketimi ve evaporatör üfleme sıcaklığındaki değişiklikler karşılaştırılabilir. 


\section{KAYNAKLAR}

[1] N. Nethaji, S. Tharves Mohideen, "Energy conservation in domestic refrigerators by cooling compressor shell - A case study," Case Studies in Thermal Engineering, vol. 10, pp. 382-387, 2017.

[2] A. Siricharoenpanich, S. Wiriyasart, R. Prurapark, P. Naphon, "Effect of cooling water loop on the thermal performance of air conditioning system," Case Studies in Thermal Engineering, vol. 15, pp. 100518, 2019.

[3] Y. Yang, C. Ren, Z. Wang, B. Luo, "Theoretical performance analysis of a new hybrid air conditioning system in hot-dry climate," International Journal of Refrigeration, vol. 116, pp. 96-107, 2020.

[4] K. Harby, F. Al-Amri, "An investigation on energy savings of a split air-conditioning using different commercial cooling pad thicknesses and climatic conditions," Energy, vol. 182, pp. 321-336, 2019.

[5] E. Hajidavalloo, "Application of evaporative cooling on the condenser of window-air conditioner," Applied Thermal Engineering, vol. 27, pp. 1937-1943, 2007.

[6] M. Hosoz, A. Kilicarslan, "Performance evaluations of refrigeration systems with air-cooled, watercooled and evaporative condensers," International Journal Of Energy Research, vol. 28, pp. 683-696, 2004.

[7] G. G. Heidingera, S. M. Nascimentoa, P. D. Gasparb, P. D. Silva, "Experimental evaluation of the thermal performance at different environmental conditions of a low temperature display case with builtin compressor and water-cooled condenser," Applied Thermal Engineering, vol. 144, pp. 825-835, 2018.

[8] A.S. Manirathnam, K. Senthil Kumar, R. Prabhu, M. Sivashankar, N. Hariharan, "Experimental study of the performance of al2o3/water nanofluid in condensing unit of air conditioner," Materials Today: Proceedings, doi: https://doi.org/10.1016/j.matpr.2020.04.011.

[9] P. S. Raveendran, S. J. Sekhar, "Performance studies on a domestic refrigerators retrofitted with building-1ntegrated water-cooled condenser," Energy and Buildings, vol. 134, pp. 1-10, 2017.

[10] Y. Erşahin, "Evaporatör ve kondenser sıcaklıklarının soğutma yüküne bağlı kontrolü ile bir soğutma grubunun veriminin değişiminin incelenmesi," Yüksek Lisans tezi, Makina Mühendisliği Bölümü, Gazi Üniversitesi, Ankara, Türkiye, 2017.

[11] A. Akçay, "Mekanik soğutma sistemlerinde kondenser sıcaklık kontrolü ile değişik soğutma kapasitelerinin sağlanması," Yüksek Lisans tezi, Makina Eğitimi Bölümü, Zonguldak Karaelmas Üniversitesi, Zonguldak, Türkiye, 2004.

[12] F. Afshari, B. Şahin, A. Khanlari, E. Manay, "Experimental optimization and investigation of compressor cooling fan in an air-to-water heat pump," Heat Transfer Research, vol. 51, no. 4, pp. 319$331,2020$.

[13] F. Afshari, O. Comaklı, Ş. Karagöz, H. Ghasemi Zavaragh, "A thermodynamic comparison between heat pump and refrigeration device using several refrigerants," Energy and Buildings, vol. 168, pp. 272-283, 2018.

[14] F. Afshari, O. Comakl1, N. Adıgüzel, H. Ghasemi Zavaragh, "Influence of refrigerant properties and charge amount on performance of reciprocating compressor in air source heat pump," Journal of Energy Engineering, vol. 143, pp. 04016025, 2017. 
[15] H. Acül, "Kanatlı borulu tip hava soğutmalı kondensenler ve sistem enerji verimliliğine etkileri," Ege Soğutma Sanayicileri ve İ̧̧ Adamları Derneği, c. 477, ss. 1-12, 2008.

[16] A. Y1ldız, "Soğutma sistemlerinde soğutma kapasitesinin adyabatik nemlendirme yöntemi kullanılarak iyileştirilmesi," Yüksek Lisans tezi, Makina Mühendisliği Bölümü, Karabük Üniversitesi, Karabük, Türkiye, 2013. 